\title{
Infected Epidermoid Cyst Including Multiple Nails at the Amputated Thumb Stump: A Case Report
}

\author{
Dae-Geun Kim, Byung Hoon Kwack \\ Department of Orthopedic Surgery, Soonchunhyang University Gumi Hospital, Soonchunhyang University College of Medicine, Gumi, Korea
}

\begin{abstract}
Fingertip amputation is a common injury among trauma occurring in the upper extremity. After amputation of the fingertip, there are several treatment options according to the degree of damage. Also, the skin flap is sometimes performed when skin defects are accompanied. Among the complications associated with fingertip injury, cyst formation at the amputation stump is rare but some cases have been reported based on the pathologic findings. There was a case of an infected epidermal inclusion cyst containing multiple nail plates at the amputation stump of the thumb, so we would like to report it with a review of the literature.
\end{abstract}

Keywords: Amputation; Fingers; Epidermal cyst; Case report

\section{INTRODUCTION}

Fingertip injury is the most common injury in the upper extremity trauma [1]. There are many situations for fingertip damage, and there are several treatment methods as a result. Therefore, there is no absolute treatment for fingertip amputation. Flap surgery is sometimes necessary if there is a skin defect. The reports of epidermoid cyst associated with flap in the hand are rare [2,3]. An epidermoid cyst is a benign tumor containing a layer composed by stratified squamous epithelium and filled with keratin, commonly occurring in the subcutaneous layer [4]. We report an infected epidermoid cyst containing multiple nails at an amputated thumb stump after the groin flap.

\section{CASE REPORT}

A 55-year-old male patient underwent several surgeries including stump revision V-Y advancement flap and groin flap at other hospital after his right thumb was amputated by a rope while working on a ship more than 20 years ago. The cystic mass of the amputation stump was gradually growing 5 years before the visit, and he complained of severe pain and tenderness 2 months ago despite antibiotic treatments.
On the physical examination, the distal phalanx of the right thumb was cut, and a hard species with an irregular surface of $2 \times 2 \mathrm{~cm}^{2}$ was palpated at the stump, and tenderness was present in this area (Fig. 1). In simple radiography, irregular calcific materials were observed to be $1.5 \times 2 \mathrm{~cm}^{2}$ in the distal part from proximal phalanx (Fig. 2). Computed tomography showed that thin and long calcific materials were clustered, and a thin film wrapped around them was observed (Fig. 3).

The authors performed an excisional biopsy on the mass. A skin incision was performed in an oval shape, and then several thin, long and rolled materials like snail shells were found as soon as the incision was made. A thin film such as jelly existed around these tissues, carefully removing the thin film until normal tissue was identified. Subsequently, several remaining calcified substances were removed using rongeur (Fig. 4).

The pathological finding of the removed materials was diagnosed as epidermoid cysts containing fingernails because removed materials had hard and thick keratin and were surrounded by squamous epidermal cells in the periphery (Fig. 5).

After surgery, the object was not touched at the left thumb amputation, and the patient did not complain of discomfort or pain. There was no recurrence or pain of the tumor after 1 year of surgery.
Correspondence to: Dae-Geun Kim

Department of Orthopedic Surgery, Soonchunhyang University Gumi Hospital, 179 1(il) Gongdan-ro, Gumi 39371, Korea

Tel: +82-54-468-9124, Fax: +82-54-468-9075, E-mail: kuro025@schmc.ac.kr

Received: Oct. 17, 2021 / Accepted after revision: Nov. 10, 2021
(C) 2021 Soonchunhyang Medical Research Institute This is an Open Access article distributed under the terms of the Creative Commons Attribution Non-Commercial License (https://creativecommons.org/licenses/by-nc/4.0/). 

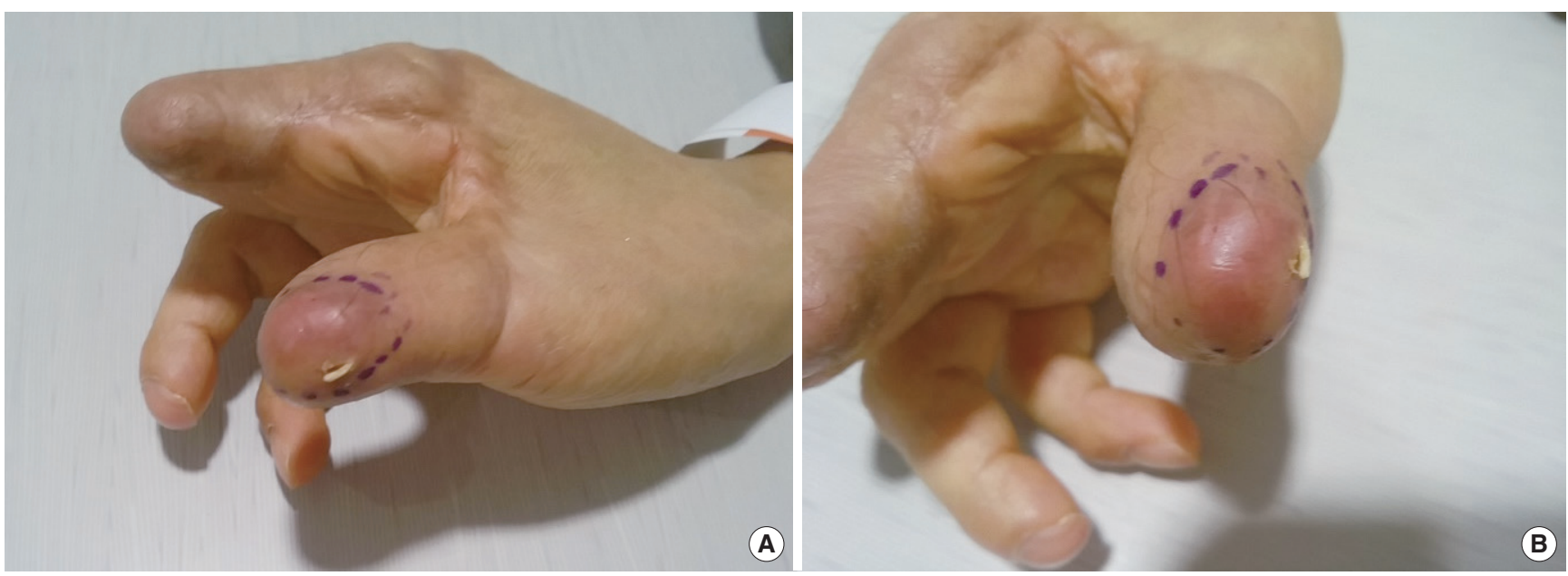

Fig. 1. (A, B) Some hard and painful $2 \times 2 \mathrm{~cm}^{2}$-sized mass was found on the right thumb. A sharp whitish material was stuck out in the dorsal side of the mass.
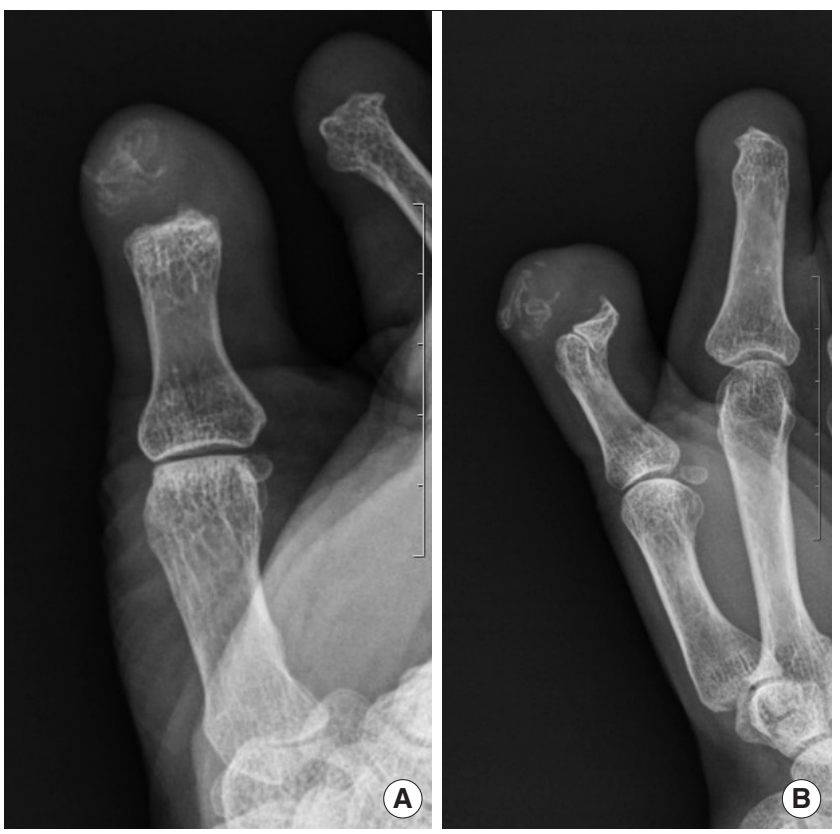

Fig. 2. (A, B) Radiographs showed right amputated thumb without distal phalanx. There were irregular surfaced calcific materials above the proximal phalanx.

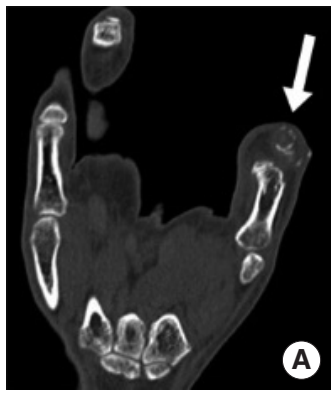

Fig. 3. (A, B) On computed tomography, sharp, irregular, and multiple calcific materials were found (arrow).
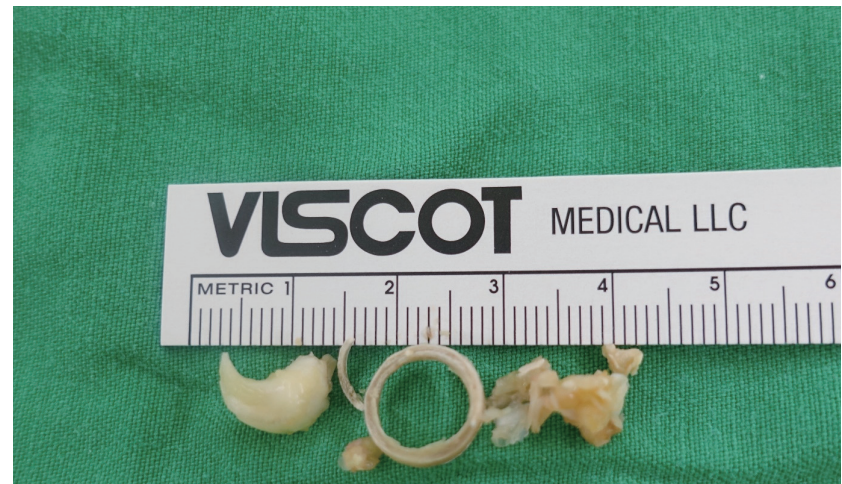

Fig. 4. The multiple hard materials were found after operation. These foreign bodies were white-colored, irregularly shaped, and hard.

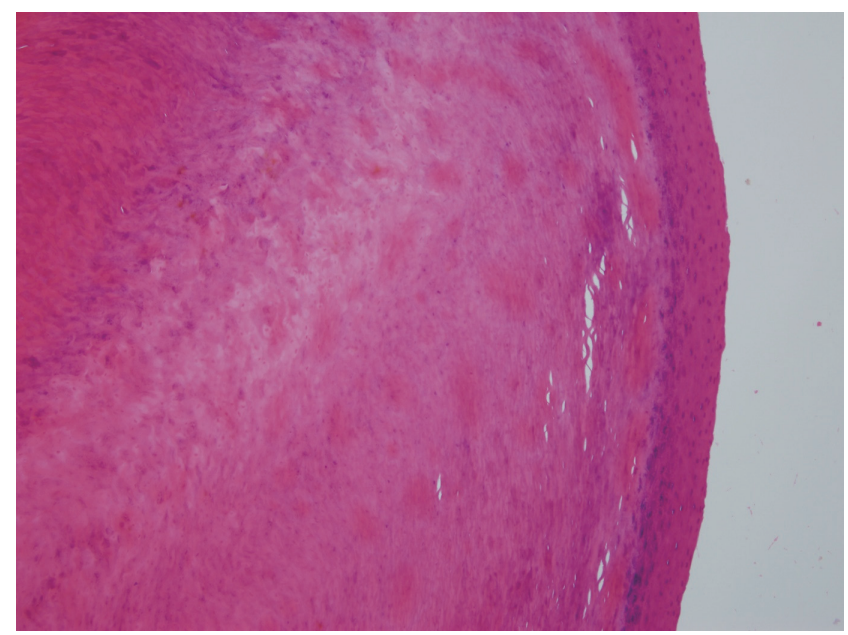

Fig. 5. Microscopic findings revealed that the cyst was composed with dense keratin with squamous epithelium $(H \& E, \times 100)$. 
The patient provided written informed consent for the publication of clinical details and images.

\section{DISCUSSION}

Fingertip injury is the most common injury to the upper extremity [1]. There are several treatment options for fingertip amputation. However, there are various complications for each treatment method, so there is controversy over the right treatments for each situation. Also, a full-thickness skin graft or flap reconstruction might be necessary if there is a skin defect. Many complications can arise after fingertip amputation, such as infection, residual pain, scar retraction, flexion contracture, cold intolerance, and flap loss [5].

Epidermal inclusion cyst is the most common cutaneous cyst, and multiple synonyms exist such as epidermoid cyst, epidermal cyst, and inclusion cyst [6]. Epidermoid cysts are surrounded by membranes composed of stratified squamous epithelial cells and are benign tumors with keratin as the main component in the center [4]. Epidermoid cysts mainly occur in subcutaneous tissues and are mainly accompanied by symptoms of edema, pain, and tenderness [4]. Epidermoid cysts that occur after damage to soft tissue, such as animal bites or laceration, can occur when epidermal cells are infiltrated [7]. However, epidermoid cysts associated with flap surgery in the hands are known to be rare $[2,3]$. Penny and Hooper [2] reported two cases of epidermoid cyst after pedicle flap for the first time. Epidermoid cyst after flap is often misunderstood as chronic osteomyelitis because symptom was not improved even though antibiotics usage [8].

In our case, after right fingertip amputation a long time ago, several surgeries including stump revision, V-Y advancement flap, and groin flap were performed. Mass was observed in the amputated stump and then had been gradually grown for 5 years. At first, the patient received antibiotics under suspicious osteomyelitis. However, the mass was growing up, and he finally visited Soonchunhyang University Gumi Hospital for the operation.

The exact cause of epidermoid cysts containing these several nail fragments is not yet known, but the authors predicted the fol- lowing hypothesis. When the hand was damaged, there was a nail matrix, but a tiny remnant of the nail matrix, especially germinal matrix, remained, and would have entered during the flap surgery. After that, it is estimated that the fingernails grew over time and gradually stimulated to produce epidermoid cysts.

In this case, an excision biopsy was performed with a painful cyst of the amputation of the right thumb, and as a result, a pathological finding of epidermoid cyst including several nail fragments was shown, and this is reported along with a review of the literature review.

\section{CONFLICT OF INTEREST}

No potential conflict of interest relevant to this article was reported.

\section{ACKNOWLEDGMENTS}

This work was supported by the Soonchunhyang University Research Fund.

\section{REFERENCES}

1. Panattoni JB, De Ona IR, Ahmed MM. Reconstruction of fingertip injuries: surgical tips and avoiding complications. J Hand Surg Am 2015;40: 1016-24.

2. Penny I, Hooper G. Nail retention cyst: a late complication of digital reconstruction using pedicle flaps. J Hand Surg Br 1989;14:345-6.

3. Kang HJ, Woo YH. Epidermoid cyst after groin flap mimicking malignancy. J Korean Soc Surg Hand 2016;21:167-72.

4. Lincoski CJ, Bush DC, Millon SJ. Epidermoid cysts in the hand. J Hand Surg Eur Vol 2009;34:792-6.

5. Kawaiah A, Thakur M, Garg S, Kawasmi SH, Hassan A. Fingertip injuries and amputations: a review of the literature. Cureus 2020;12:e8291.

6. Weir CB, St. Hilaire NJ. Epidermal inclusion cyst [Internet]. Treasure Island (FL): StatPearls Publishing; 2021 [cited 2021 Oct 15]. Available from: https://www.ncbi.nlm.nih.gov/books/NBK532310/.

7. Hwang SM, Kim HI, Ahn SM, Lim KR, Jung YH, Song JK. Multiple epidermal inclusion cysts in previous bone graft site of the thumb: a case report. J Korean Soc Surg Hand 2011;16:247-50.

8. Park MR, Lee KH, Lim KM. Inclusion cyst after flap surgery for thumb degloving injury: report of one case. J Korea Soc Surg Hand 1997;2:154-7. 